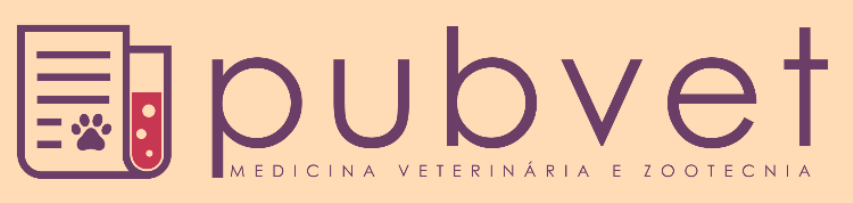

https://doi.org/10.31533/pubvet.v14n6a600.1-4

\title{
Agenesia da veia cava caudal com drenagem pela veia ázigos em cão da raça Scott Terrier: relato de caso
}

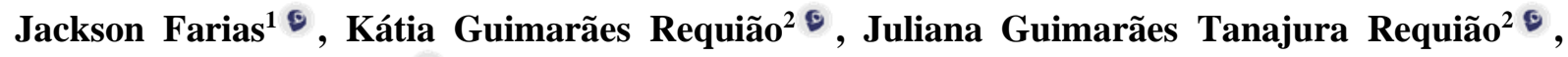 \\ Rodrigo Lima Carneiro ${ }^{\circ}$, Ana Manuella Souza de Babo ${ }^{4}$ \\ ${ }^{I}$ Graduando na Universidade do Estado da Bahia, Campus-IX. Barreiras-Ba Brasil. \\ ${ }^{2}$ Médica Veterinária autônoma, Serviço Médico Veterinário - SEMEVE. Salvador - Ba Brasil. \\ ${ }^{3}$ Professor substituto na Universidade do Estado da Bahia, Campus-IX. Barreiras-Ba Brasil. \\ ${ }^{4}$ Professora na Faculdade Regional da Bahia- UNIRB. Barreiras-Ba Brasil. \\ *Autor para correspondência, E-mail: jacksonpratesfarias51@gmail.com
}

\begin{abstract}
Resumo. A agenesia da veia cava caudal é uma malformação que ocorre ainda no período da embriogênese, tendo como característica a ausência parcial ou total do órgão. Por se tratar de uma anormalidade às vezes assintomática, são achados raros encontrados em exames de imagem, podendo ser desde uma simples ultrassonografia, a uma tomografia computadorizada, sendo os mesmos os principais métodos para a detecção e fechamento do diagnóstico. Este trabalho tem como objetivo relatar um caso de um cão da raça Scott Terrier, de 8 anos e 4 meses, atendido em um hospital veterinário na cidade de Salvador-BA, que após a realização de ultrassom e tomografia, confirmou-se a agenesia da veia cava caudal.
\end{abstract}

Palavras chave: bioimagem, má formação, tomografia computadorizada, ultrassonografia

\section{Caudal vena cava agenesis with azygos vein drainage in a Scott Terrier dog: case report}

\begin{abstract}
The caudal vena cava agenesis is a malformation that occurs during the embryogenesis period, characterized by partial or total absence of the organ. Because it is a sometimes-asymptomatic abnormality, they are rare findings on imaging exams, which can range from simple ultrasound to computed tomography, and are the main methods for detection and closure of the diagnosis. This paper aims to report a case of a Scott Terrier dog, aged 8 years and 4 months, treated at a Veterinary Hospital in the city of Salvador-BA, which, after performing ultrasound and tomography, confirmed the agenesis of the caudal vena cava.
\end{abstract}

Keywords: bioimaging, malformation, computed tomography, ultrasound

\section{Agenesia de la vena cava caudal con drenaje de la vena ácigos en un perro Scott Terrier: reporte de un caso}

Resumen. La agenesia de la vena cava caudal es una malformación que ocurre durante el período de embriogénesis, caracterizada por la ausencia parcial o total del órgano. Debido a que es una anormalidad a veces asintomática, son hallazgos raros em los exámenes de imágenes, que pueden variar desde un simple ultrasonido hasta una tomografía computarizada, siendo los principales métodos para la detección y el cierre del diagnóstico. Este documento tiene como objetivo informar un caso de un perro Scott Terrier, de 8 años y 4 meses, tratado en un Hospital Veterinario en la ciudad de Salvador-BA, que, después de realizar una ecografía y una tomografía, confirmo la agenesia de la vena cava caudal.

Palabras clave: bioimagen, malformación, tomografía computarizada, ultrasonido 


\section{Introdução}

A veia cava caudal é um vaso sanguíneo encontrado na região abdominal iniciando-se na última vértebra lombar dos animais pelo encontro da veia sacral mediana e das veias ilíacas (Köning \& Liebich, 2011). Essa importante veia desempenha um papel fundamental em todo o processo de circulação sanguínea, permitindo que o sangue desoxigenado de toda parte posterior do organismo seja levado para a anterior, que por sua vez, está ligada diretamente ao átrio direito do coração, o que possibilita que ocorra a circulação sistêmica normal do animal (Frandson et al., 2011; Ortale et al., 2005).

A ázigo, veia que atravessa todo o hiato aórtico para adentrar a região torácica, tem na sua formação a junção das duas primeiras veias lombares recebendo o sangue que vem das veias intercostais, caudal e média, da cavidade torácica e contribui para a drenagem do canal vertebral. No processo embrionário, os cães apresentam tanto a ázigo direita quanto a esquerda, mas apenas a primeira permanece (Köning \& Liebich, 2011).

O termo utilizado no vocabulário médico para referir-se à ausência total de um órgão em determinado indivíduo denomina-se agenesia (Gensas et al., 2012; Kumar, 2010). Na medicina veterinária a agenesia da veia cava caudal é um evento raro de se ocorrer assim como na medicina humana. Essa malformação ocorre na embriogênese, obrigando que o organismo busque outras formas para compensar a ausência do órgão, permitindo que este não venha a óbito. Em alguns casos, a anomalia em questão pode vir de forma assintomática, não demonstrando nenhum sinal no estado de saúde do animal no decorrer de sua vida (Gensas et al., 2012).

A agenesia pode acometer diferentes estruturas dos animais, atingindo tecidos, ossos e órgãos, sendo relatada em cães sem raça definida, mas na sua maioria, nos animais de raça. Essas alterações na maioria das vezes são encontradas após os exames de imagem, sendo de extrema importância o fechamento precoce do diagnóstico para evitar maiores transtornos ao paciente e proporcionar uma qualidade de vida melhor.

Em dois animais, um da raça Yorkshire e o outro sendo um Rottweiler, apresentaram anormalidade diferente, sendo elas, a agenesia unilateral de olécrano no primeiro, e no segundo, agenesia focal proximal do fêmur. Nestes trabalhos, defende-se a ideia de uma má formação congênita como o verdadeiro motivo da presença na anomalia (Campos et al., 2013).

Com este trabalho, teve-se o objetivo de relatar um caso de agenesia em cava caudal (VCC), por drenagem da veia ázigo, em um cão de 8 anos e 4 meses de idade, macho, da raça Scott Terrier, atendido em um hospital veterinário na cidade de Salvador - BA. Este relato torna-se único na bibliografia nacional, por ser o primeiro caso descrito.

\section{Relato de caso}

Um animal da espécie canina, da raça Scott Terrier, de 8 anos e quatro meses de idade, chegou ao hospital para atendimento clínico, para avaliação de uma neoformação verrucosa localizada em porção frontal da cabeça, observada pela tutora e consulta geriátrica. Feito a anamnese e exame físico, foi solicitado exames laboratoriais.

No dia 14/01/2019 realizou-se o exame de ultrassonografia abdominal, que por meio deste, evidenciou-se que a glândula adrenal direita apresentava em seu polo cranial, uma imagem arredondada, discretamente hiperecogênica e com ecotextura "grosseira", medindo 2,90 cm de diâmetro. A veterinária radiologista sugeriu para melhor caracterização da formação visualizada, prosseguir com a investigação propedêutica e realizar uma tomografia computadorizada-TC, uma vez que, receou-se uma compressão da veia cava cauda localizada anatomicamente próxima a glândula.

Após dois dias da realização do primeiro exame de imagem, o animal retornou ao estabelecimento, em jejum, para ser submetido à tomografia computadorizada. Para que fosse realizado o procedimento diagnóstico, foi necessária a solicitação de exames complementares como eletrocardiograma, para maior segurança ao ato anestésico necessário para a realização do exame tomográfico.

A TC iniciou-se pelo tórax com a aplicação de contraste por via intravenosa para melhor definição de anormalidades que ali pudessem estar presentes. Com a análise das imagens, a aorta e outras estruturas vasculares do mediastino apresentavam topografia habitual e calibre dentro da normalidade, 
exceto a veia ázigo, que apresentava calibre aumentado semelhante a aorta. Ato contínuo realizou-se varredura da região abdominal em busca de maiores achados e confirmação de resultados.

$\mathrm{Na}$ avaliação abdominal, obtiveram-se várias impressões importantes para a confirmação diagnóstica, na qual foi possível observar a agenesia da veia cava caudal hepática e pré-hepática. Dessa maneira, o retorno venoso estava sendo realizado pela veia ázigo, de forma compensatória, para suprir a ausência da veia cava caudal. Os achados demonstraram um calibre da ázigo superior ao normal, medindo cerca de $0,90 \mathrm{~cm}$ de diâmetro, sendo este muito semelhante ao diâmetro da aorta. Incluía ainda uma bifurcação na região da L5, recebendo as veias renais direita e esquerda em correspondência a L4, inserindo-se no segmento terminal da veia cava cranial, próximo da inserção no átrio direito. As veias hepáticas por sua vez, sofriam confluência unindo-se na altura da cúpula diafragmática para a formação da veia cava caudal pós-hepática.

\section{Discussão}

A agenesia da veia cava caudal ocorre ainda na fase de desenvolvimento embrionário de homens e outros animais. Relatos de casos na área são escassos por se tratar de um achado incomum e ocasional durante a realização de exames de rotina que envolve a procura de outros distúrbios (Lockwood et al., 2018). Outro fator que leva a sua subnotificação é a ausência, na maioria dos casos, de sintomatologias relacionadas ao evento (Gensas et al., 2012).

Literaturas veterinárias encontradas nas bases de dados nacionais não trazem estudos quantitativos acerca de tal má-formação. No entanto, a medicina humana relata que se trata de uma anomalia rara com incidência de $0,005 \%$ a $1 \%$ na população. No entanto, as principais causas de sua ocorrência são a trombose intrauterina e perinatal (Gensas et al., 2012). Yang et al. (2013), em seu artigo, explica que a agenesia da VCC intra-hepática com continuação da ázigos pode ser um defeito na fase embriológica, mais específica na anastomose subcardino-hepática e, como consequência, ocorre um desvio do sangue para a veia ázigos. Os mesmos autores ainda afirmam que essa alteração tem associação com várias síndromes, como asplenia, heterotaxia e poliesplenia.

Segundo Konopka et al. (2010), há uma discussão na literatura sobre a real causa da agenesia da VCC. Alguns autores acreditam que a trombose no período perinatal sejam a verdadeira responsável pela não formação da estrutura, e outros, defendem a tese de um evento congênito decorrente de alguma anormalidade, podendo ela ser por problemas esplênicos, disgenesia pulmonar, agenesia renal e doenças cardíacas.

\section{Conclusão}

O cão não necessitou de nenhum tipo de tratamento ou intervenção cirúrgica decorrente da agenesia. Após a descoberta, continuou realizando exames para acompanhamento da sua saúde a fim de evitar uma possível alteração. Com este relato inovador, se abre portas para novos estudos de agenesia em animais na medicina veterinária.

\section{Referências bibliográficas}

Campos, W. N. S., Meireles, Y. S., Shinike, F. S., Santos, J. G., Peres, T. P., Pytlak, D. B., Nespoli, P. B., \& Souza, R. L. (2013). Unilateral agenesis olecranon in the dog-first case report. Acta Veterinaria Brasilica, 7(Suppl. 1), 518-519.

Frandson, R. D., Wilke, W. L., \& Fails, A. D. (2011). Anatomia e fisiologia dos animais de fazenda. Guanabara Koogan.

Gensas, C. S., Pires, L. M., Kruse, M. L., Leiria, T. L. L., Gomes, D. G., \& Lima, G. G. (2012). Agenesia da veia cava inferior. Revista Brasileira de Cardiologia Invasiva, 20(4), 427-430. DOI: https://doi.org/10.1590/S2179-83972012000400015

Köning, H. E., \& Liebich, H. G. (2011). Anatomia dos animais domésticos texto e atlas colorido. Editora Artmed.

Konopka, C. L., Salame, M., Padulla, G. A., Muradás, R. R., \& Batistella, J. C. (2010). Agenesia de veia cava inferior associada à trombose venosa profunda. Jornal Vascular Brasileiro, 9(3), 196-199. DOI: https://doi.org/10.1590/S1677-54492010000300019 
Kumar, V. (2010). Robbins \& cotran-patologia bases patológicas das doenças. Elsevier Brasil.

Lockwood, A. J., Sinnott-Stutzman, V. B., Mouser, P. J., \& Tsai, S. L. (2018). Azygos continuation of the caudal vena cava with segmental aneurysm, lung lobe torsion and pulmonary thromboembolism in a dog. Clinical Case Reports, 6(2), 363.

Ortale, J. R., Meciano Filho, J., Paccola, A. M., Leal, J. G. P. G., \& Scaranari, C. A. (2005). Anatomia dos ramos lateral, diagonal e ântero-superior no ventrículo esquerdo do coração humano. Revista Brasileira de Cirúrgia Cardiovascular, 20(2), 149-158. DOI: https://doi.org/10.1590/S010276382005000200010

Yang, C., Trad, H. S., Mendonça, S. M., \& Trad, C. S. (2013). Anomalias congênitas da veia cava inferior: revisão dos achados na tomografia computadorizada multidetectores e ressonância magnética. Radiologia Brasileira, 46(4), 227-233.

Recebido: 9 de março, 2020.

Aprovado: 25 de maio, 2010.

Disponível online: 16 julho, 2020.

Licenciamento: Este artigo é publicado na modalidade Acesso Aberto sob a licença Creative Commons Atribuição 4.0 (CC-BY 4.0), a qual permite uso irrestrito, distribuição, reprodução em qualquer meio, desde que o autor e a fonte sejam devidamente creditados. 